Recebido: 06/11/2014

Aprovado: 04/12/2014

\title{
A Independência do Brasil, a Construção do Conhecimento Histórico e a Formação para a Cidadania, a partir dos Livros Didáticos
}

Joyce Karla Pereira*

Resumo: Neste artigo, apresenta-se um estudo acerca da formação para a cidadania e sua relação com a temática da Independência do Brasil, a partir da análise dos conteúdos de livros didáticos adotados pelas escolas da cidade de Lavras, Minas Gerais. A análise parte do discurso das Diretrizes Nacionais de Ensino, que aponta a formação para a cidadania como o principal objetivo do ensino de História, relacionado aos estudos do tema historiográfico desenvolvidos na perspectiva de uma Nova História Política. Desta forma, busca-se compreender essa formação para a cidadania, na sua relação com o conhecimento histórico.

Palavras-chave: livros didáticos; História Política; Independência do Brasil.

Abstract: This article shows a study about citizenship development and its relationship with the Independence of Brazil from the analysis of textbooks used in schools in Lavras, Minas Gerais. The analysis is based on the discourse of National Education Guidelines - Diretrizes Nacionais de Ensino - that points out the citizenship development as the main purpose of teaching History, related to the historiographical studies developed in the perspective of a New Political History. Thus, it seeks to understand the citizenship development and its relation with the historical knowledge. Keywords: Textbooks; Political History; Brazil's Independence.

\footnotetext{
* Mestra em História pela Universidade Federal de São João del-Rei.
} 
Segundo a Lei $\mathrm{n}^{\circ}$ 9.394, de 20 de dezembro de 1996, que estabelece as diretrizes e bases da educação nacional,

a educação, dever da família e do Estado, inspirada nos princípios de liberdade e nos ideais de solidariedade humana, tem por finalidade o pleno desenvolvimento do educando, seu preparo para o exercício da cidadania e sua qualificação para o trabalho. (BRASIL, Lei nº 9.394, de 20 de dezembro de 1996, 1996).

O Estado não só assume parte do dever para com a educação, como aponta a mesma como um preparo para o exercício para a cidadania. A educação, para além do seu papel pedagógico, assume, também, um caráter político, uma vez que está intrinsecamente ligada ao Estado por meio de sua Constituição, e, porque este utiliza a mesma como um instrumento para a formação de seus cidadãos.

A vinculação entre educação e participação política é uma constante desde os liberais do Império, até os liberais e progressistas de todas as repúblicas. Casemiro Reis Filho (1981: 178), em sua documentada análise sobre A educação e a ilusão liberal, mostra que já no século passado 'a educação consistia no mais eficiente instrumento para a construção de um Estado republicano democrático. Acreditavam que um regime político que se definia como sendo do povo e para o povo necessitava de uma sólida organização escolar capaz de oferecer uma formação política, a mais completa possível, a todos os cidadão. (BUFFA et al., 2003: 31)

A formação para a cidadania é elemento central nas diretrizes educacionais, inclusive como justificativa para a necessidade da elaboração dos Parâmetros Curriculares Nacionais $(\mathrm{PCN})$.

Os Parâmetros Curriculares Nacionais foram elaborados procurando, de um lado, respeitar diversidades regionais, culturais, políticas existentes no país e, de outro, considerar a necessidade de construir referências nacionais comuns ao processo educativo em todas as regiões brasileiras. Com isso, pretende-se criar condições, nas escolas, que permitam aos nossos jovens ter acesso ao conjunto de conhecimentos socialmente elaborados e reconhecidos como necessários ao exercício da cidadania. (BRASIL, 1998: 5).

No discurso dos Parâmetros Curriculares Nacionais, a formação para a cidadania passa pela aproximação entre o aluno e o conteúdo estudado. Tal aproximação tem sido relacionada, diretamente, com o estudo de uma História voltada para o cotidiano, para questões sociais, com as quais os alunos possam se identificar e, assim, perceberem-se como sujeitos da História.

Os PCN questionam os métodos e as concepções concebidos como tradicionais e afirmam que os estudos no campo da produção do 
conhecimento histórico, nas últimas décadas, têm proporcionado novos olhares aos historiadores, professores e alunos. Esses estudos têm refletido criticamente sobre os agentes condutores da história, os povos e culturas sobre os quais os estudos históricos devem lançar seus olhares, as fontes utilizadas pelos historiadores, as noções de tempo histórico e as relações entre a História e outras disciplinas.

Ao refletir acerca dessas transformações, os PCN assumem uma posição signatária das chamadas novas tendências, especialmente da Nova História, condenando a concepção de História voltada para a legitimação de determinados setores, tidos como únicos sujeitos da História. (NETO, 2009: 8).

A ideia de aproximar os alunos dos conteúdos ensinados na disciplina de História leva a uma predileção pela História do cotidiano, do privado, da cultura, e não considera a dimensão política da vida social. A centralidade da formação da cidadania como a possibilidade de participação na vida política e sua relação com o Estado não é mencionada no discurso dos PCN, e a complexidade das relações políticas é minimizada no conteúdo dos livros didáticos.

O presente artigo $^{1}$ apresenta a Nova História Política como uma possibilidade para uma efetiva construção de um conhecimento histórico que forme para a cidadania, tendo como recorte historiográfico o processo de Independência do Brasil. Neste recorte é possível perceber experiências de cidadania e importantes transformações políticas na constituição do Estado brasileiro.

Para realizar esta discussão, que abrange o ensino de História, o discurso das diretrizes nacionais, o conteúdo dos livros didáticos e a formação para a cidadania, são fontes quatro livros didáticos adotados pelas escolas públicas e particulares da cidade de Lavras, Minas Gerais, para o triênio 2011 - 2013 do Ensino Fundamental II: Projeto Araribá (APOLINÁRIO, 2007), Para Viver Juntos (REIS e MOTOOKA, 2009), História Sociedade e Cidadania (BOULOS, 2009) e Projeto Radix (VICENTINO, 2009).

\section{Os livros didáticos de História: uma fonte histórica muito complexa.}

Livros didáticos são fontes históricas que possibilitam uma gama de estudos e reflexões sobre o ensino de História, a concepção de História e o conhecimento histórico que é transmitido, ou que se pode construir, a partir dos mesmos, e, também, são um viés para a análise da atuação das instâncias governamentais na educação, já que o processo de elaboração dos livros

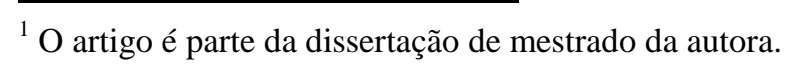


se insere num amplo contexto de relações que envolvem investimentos financeiros, organização, coordenação, divisão de trabalho, papéis e funções de muitas pessoas, criatividade, concepções várias e diferenciadas com a finalidade de atender a um 'mercado' em conformidade com as exigências do governo e sua ideologia e também às circunstâncias culturais e sociais. (PURIFICAÇÃO, 2002: 64).

Esses elementos que envolvem a elaboração, publicação, distribuição e utilização dos livros didáticos, têm sido tema de inúmeros estudos que contribuem para a análise dos mais diversos âmbitos do ensino de História e das políticas públicas de ensino. Em sua dissertação de mestrado, Yara Cristina Alvim em pesquisa ao portal Capes, traça algumas tendências gerais que caracterizam a pesquisa acerca dos livros didáticos, a partir da década de 1990, sendo possível

perceber que os livros didáticos passaram a ser analisados nos últimos anos sob uma perspectiva didática, contribuindo para a construção de análises diferenciadas relativas ao conteúdo do livro didático. Além disso, convém ressaltar que o livro didático passou a ser analisado, também, a partir de sua relação com as práticas escolares. As formas de apropriação do livro didático por parte de professores e de alunos no interior da instituição escolar tornaram-se recorrentes nesse tipo de pesquisas. Muitas delas passaram a se debruçar sobre os usos que professores e alunos fazem do livro didático na sala de aula. (ALVIM, 2010: 39)

Para analisar um recorte historiográfico, a partir dos livros didáticos, há que se levar em consideração a maneira como as vertentes historiográficas perpassam os mesmos, como se adequam a eles, quais elementos são desenvolvidos nos livros e quais deixam a desejar. Objetiva-se, com essa postura, impedir que o trabalho se torne uma militância em defesa de uma vertente historiográfica, em detrimento de outras, o que seria pouco enriquecedor para o estudo, porque a História se constrói, exatamente, a partir da discussão entre as suas várias vertentes e não da superação delas.

À essa discussão sobre a produção historiográfica nos livros didáticos, este artigo propõe uma reflexão sobre a importância de uma leitura que retome elementos da História Política, porque

a cultura política é uma chave. Ela introduz a diversidade, o social, ritos símbolos, lá onde se acredita que reina o partido, a instituição, o imutável. Ela permite sondar os rins e os corações dos atores políticos. Seu estudo é mais que enriquecedor, é indispensável. (BERSTEIN apud FERREIRA, 1992: 267).

A História Política que foi questionada pelo Marxismo, e, por vezes, é vista como a antítese do que propõe a Nova História, é entendida, neste trabalho, como importante viés para o estudo da História, especialmente para esta proposta que é compreender como o ensino de História contribui na formação para a cidadania, levando em consideração 
que o político não interessa subjetivamente apenas aos políticos profissionais, nem se reporta objetivamente só a eles. Pensando bem, praticamente não existe outra atividade que atinja um número maior de homens e mulheres, pelo menos nos países democráticos. O princípio segundo o qual todos os cidadão são iguais entre si e são chamados a participar das grandes escolhas políticas faz da política a 'coisa de todos'. Mesmo que nem todos façam uso desse direito, todos são chamados, todos estão comprometidos. De outro lado, a política, o que é decidido, não lhes é indiferente. (...) Mesmo que não se interessem pela política, a política os alcança. (REMOND, 1994: 18).

O ensino de História e também os livros didáticos, ao longo dos anos modificaram-se adotando, ou destacando, linhas historiográficas diferentes, de acordo com o momento histórico no qual estavam inseridos. Há momentos de "superação" de uma vertente historiográfica por outra, o que indica uma concepção de linearidade da História, bem como da historiografia.

Poder e política passaram a ser entendidos como domínios das representações sociais, com suas conexões e práticas associadas ao simbólico e às formas simbólicas. A reinterpretação dos elementos que corporificam a política e o poder: as relações sociais e coletivas, os imaginários sociais, a memória ou memórias coletivas, as mentalidades e as práticas discursivas associadas ao poder direcionaram os estudos políticos para o universo societário de tal maneira que, não se estuda mais a política apenas como estudo do Estado ou das guerras, mas, como ação negociada e forjada na sociedade em conexão com a cultura. (SANTOS NETO, 2008: 139).

O estudo do político não restringe o ensino ao estudo dos grandes chefes de Estado. Ao contrário, permite a compreensão também da sociedade que constrói o contexto no qual esse chefe de Estado está inserido, e cuja organização explica o porquê da estruturação do cenário político, no qual todos os sujeitos estão inseridos, sendo eles participantes diretos, ou não.

\section{A formação para a cidadania}

A formação para a cidadania é uma constante em todos os aspectos que envolvem o livro didático, porque está no texto das diretrizes da educação que influenciam a elaboração do conteúdo dos livros. O primeiro objetivo do Ensino Fundamental, segundo os Parâmetros Curriculares Nacionais (PCN) é

Compreender a cidadania como participação social e política, assim como exercício de direitos e deveres políticos, civis e sociais, adotando, no dia a dia, atitudes de solidariedade, cooperação e repúdio às injustiças, respeitando o outro e exigindo para si o mesmo respeito. (BRASIL, 1998: 7)

\section{Fillistorórias}


Mas, o que significa formar para a cidadania? Segundo o Dicionário Houaiss cidadania significa "condição de quem, como membro de um Estado se acha no gozo de direitos que lhe permitem participar da vida política" (HOUAISS, 2001), mas cidadania remonta também

ao termo cidadão (cidadã + -ão) que, na Grécia antiga, significava o indivíduo que desfrutava do direito de participar da vida política da cidade, o que era vedado à mulher, ao estrangeiro e ao escravo e, na Roma antiga, o indivíduo nascido em território romano que gozava da condição de cidadania. Atualmente, o termo cidadão significa indivíduo que, como membro de um Estado, usufrui de direitos civis e políticos garantidos pelo mesmo Estado e desempenha os deveres que, nesta condição, lhe são atribuídos ou ainda indivíduo que goza de direitos constitucionais e respeita as liberdades democráticas. (GATTI Júnior, 2007: 23)

A cidadania está historicamente ligada ao Estado, à participação política, à organização da sociedade, mas ao longo da História assume inúmeros significados. Pensando o significado do ser cidadão nos tempos coloniais, Maria Fernanda Baptista Bicalho atenta para o

Deslocamento da noção de cidadão - morador da cidade e portador de privilégios concedidos pelo rei - para a formulação do conceito de cidadania, forjado na filosofia política do liberalismo e na experiência histórica de organização dos Estados Nacionais e de novas formas de governo - como as Monarquias Constitucionais e, em última instância, as Repúblicas. Nestas, teoricamente, os cidadãos deixariam de ser portadores de privilégios para se tornarem sujeitos - ou detentores de direitos civis e políticos. (BICALHO, 2003: 148)

Cidadania, por vezes, representa a ideia de superação das diferenças na participação política e acesso a direitos, como o termo parece hoje querer transmitir.

O século XX viu surgir no Brasil outras concepções de cidadania, não necessariamente relacionadas ao exercício do direito político de voto. A cidadania também foi pensada e proposta como defesa de direitos civis e garantia de direitos sociais, forjando-se uma multiplicidade de concepções do que é ser cidadão. (BICALHO, 2003: 148)

Essa multiplicidade de concepções que emana do termo cidadania é mencionada no discurso do PCN, retirando a centralidade da cidadania relacionada à participação política e ao Estado.

Do ponto de vista da historiografia e do ensino de História, a questão da cidadania tem sido debatida como um problema fundamental das sociedades deste final de milênio. Se em outras épocas a sua abrangência estava relacionada principalmente à questão da participação política no Estado, aliando-se à questão dos direitos sociais, hoje sua dimensão tem sido sistematicamente ampliada para incluir novos direitos conforme as 
condições de vida do mundo contemporâneo. Têm sido reavaliadas as contradições e as tensões manifestas na realidade ligadas ao distanciamento entre os direitos constitucionais e as práticas cotidianas. Assim, a questão da cidadania envolve hoje novos temas e problemas tais como, dentre outros: o desemprego; a segregação étnica e religiosa; o reconhecimento da especificidade cultural indígena; os novos movimentos sociais; o desrespeito pela vida e pela saúde; a preservação do patrimônio histórico-cultural; a preservação do meio ambiente; a ausência de ética nos meios de comunicação de massa; o crescimento da violência e da criminalidade. (BRASIL, 1998: 37)

O governo toma pra si a obrigação de garantir que a educação forme cidadãos conscientes e participantes. Entretanto, a formação para a cidadania também implica na construção de uma limitação para a atuação das instâncias superiores, uma vez que a cidadania, atualmente, também pressupõe aquisição de direitos políticos de uma maioria que assim ver-se-ia protegida do controle de uma minoria, mas o que, em contrapartida, poderia promover uma ditadura das maiorias. (GOMES, 2003: 152)

Portanto, quando o ensino tem como objetivo a formação para a cidadania, são todas essas questões que devem, ou deveriam, ser pensadas na elaboração dos livros didáticos. Questões estas que orientam a discussão do presente artigo sobre o ensino de História e a formação para a cidadania.

\section{Breve discussão historiográfica acerca da Independência do Brasil.}

A formação para a cidadania, bem como a própria noção de cidadania e as discussões envolvendo a elaboração dos livros didáticos, o ensino para a construção da cidadania, podem ser pensados dentro do processo de Independência do Brasil. Isso, porque a Independência foi um processo de constituição do Estado autônomo e das primeiras experiências de cidadania, além de constituir-se simbolicamente como momento de fundação da Nação.

Desde sua proclamação, aos 7 de setembro de 1822, às margens do Ipiranga, a Independência do Brasil vem sendo contada de muitas maneiras. Cada uma dessas leituras revela muito, não apenas sobre este processo, mas também sobre os contextos nos quais e para os quais essas interpretações foram construídas.

Jurandir Malerba, ao apresentar novas dimensões para o estudo da Independência do Brasil, aponta importantes pontos de discussão historiográfica com relação a esse processo: a construção da nação, o peso da unidade territorial, o deslocamento da periodização, caráter e sentido da Independência e a participação das camadas populares (MALERBA, 2006). Essas questões fomentam apaixonadas discussões acadêmicas que tornam mais complexa a história da Independência, uma vez que obrigam o diálogo entre várias vertentes historiográficas. 
Como compreender que a Independência tenha sido simultaneamente uma revolução liberal, uma transição pacífica, um desquite amigável, uma revolução de ampla repercussão popular e uma reação conservadora, senão por intermédio de circunstâncias densas e intrincadas, que na multiplicidade de seus desdobramentos possibilitaram e possibilitam leituras múltiplas? (OLIVEIRA. 1999: 59).

No afã de construir uma ideia de nacionalidade para a nação independente, Francisco Adolpho Varnhagen abre o leque das múltiplas leituras do processo de Independência, apresentando-a como uma espécie de ordem natural dos acontecimentos que levou a colônia a tornar-se independente, como se este fosse o desfecho desejado por todas as regiões sobre as quais impuseram o domínio colonial.

A interpretação desenvolvida por Varnhagen para a formação da nação brasileira não apenas enfatizou as continuidades entre a Colônia e o período nacional, como atribuiu a essas continuidades conotação fortemente positiva: valorizava-se com ela a obra civilizadora da monarquia portuguesa e seu papel na construção da nação. $O$ Brasil independente, colônia que amadureceu para se tornar nação sob a égide benevolente da mãe-pátria, expressava em Varnhagen, a vitória da civilização européia sobre a barbárie autóctone. (COSTA in JANCSÓ, 2005: 58).

Varnhagen inaugura a historiografia nacional ${ }^{2}$, escrevendo uma História Política na qual podemos perceber uma "visão progressiva e linear [que] transmite a falsa impressão de que a história é construída por uma sequência de etapas que cumprem uma trajetória determinada como roteiro imutável” (CAIMI et al., 2002: 61). A ênfase de sua obra recai sobre a estrutura política, na qual a figura do príncipe regente "emergia como diretamente responsável pelo sucesso da empreitada e pela manutenção da unidade territorial e política do Brasil” (COSTA in JANCSÓ, 2005: 58), além de atribuir à instauração da Monarquia a manutenção da unidade política do território pós-Independência.

A obra de Varnhagen insere-se na historiografia patrocinada pela Coroa (COSTA in JANCSÓ, 2005: 57), que buscava enaltecer a manutenção da Monarquia, concepção esta que foi "divulgada pela maioria dos publicistas e cronistas ligados à Coroa, forjando uma versão histórica de longa vigência" (COSTA in JANCSÓ, 2005: 60) no Brasil. Essa versão histórica foi alvo de uma revisão.

A revisão que começou com os publicistas liberais e emergiu com maior força no republicanismo radical mudou a maneira de encarar a emancipação política, mesmo depois de estarem ultrapassados os aspectos mais férvidos

\footnotetext{
${ }^{2}$ Segundo Wilma Peres Costa a obra fundadora da historiografia nacional, A História Geral do Brasil (1854) Varnhagen p. 57
} 
do republicanismo. Entre outras mudanças ela tendeu a reduzir o papel do príncipe D. Pedro no desencadear dos acontecimentos e a lançar luz sobre outros episódios do processo de ruptura, como o processo constituinte e a elaboração das instituições. (COSTA in JANCSÓ, 2005: 63).

Importante salientar que o fato de uma concepção historiográfica ser submetida a revisões não promove sua imediata superação, porque a historiografia não é linear. Não há intenção, neste artigo, de apresentar a historiografia detalhada da Independência do Brasil, mas, sim, pontuar elementos e características das vertentes historiográficas que possam mostrar como a Independência é entendida, a partir de cada vertente.

Não parece exagero afirmar que o enquadramento teórico predominante e mais influente na historiografia da Independência, pelo menos desde os anos 1960, é aquele derivado da abordagem de Caio Prado Júnior. Partindo de um ponto de vista marxista, ele procurou entender o "sentido" da colonização, inserindo a história do Brasil num contexto senão planetário, pelo menos ocidental. A história do Brasil explicar-se-ia, nessa ótica, como um derivativo da história europeia, no contexto da expansão do capitalismo comercial. Nessa tese jaz a base das teorias da dependência. (MALERBA, 2006: 38).

O processo de separação entre Brasil e Portugal, nesse enquadramento teórico, é entendido, a partir da crise do Antigo Regime, considerando a existência de um desejo de emancipação política e econômica liderado por uma elite colonial que influenciou as atitudes do príncipe regente, Dom Pedro. A elite colonial formada no Brasil teria passado a pensar com autonomia a respeito de seus interesses, que divergiam dos interesses metropolitanos, e tal divergência, somada às ideias iluministas que questionam o Antigo Regime construíram um sentimento de nacionalismo anticolonialista (NOVAIS; MOTA, 1996). Assim, a Independência do Brasil é vista como resultado de um projeto de separação articulado pelas elites coloniais e o Sete de Setembro como um divisor de águas da condição da colônia explorada para a nação soberana, atendendo às expectativas de liberdade política e econômica da colônia.

A visão dominante é a da centralidade da Coroa, com suas instituições, o seu direito e seus oficiais. A sobrevivência dessa imagem pode ser explicada por uma interpretação ingênua - ainda que ideologicamente significativa - das instituições históricas, fundada em preconceitos enraizados acerca da relação colonial. (HESPANHA in FRAGOSO et al., 2001: 167).

A ingenuidade à qual Antônio Manuel Hespanha se refere, trata-se de um olhar diferente sobre as fontes e os acontecimentos históricos. A exploração e o pacto colonial existiram, influenciaram a formação da sociedade colonial, e os rumos políticos que ela veio a tomar. Logo, a análise sobre a colônia deve ser feita, a partir dessa realidade, ou seja, da relação existente entre colônia e metrópole. Mas, faz-se necessário levar em consideração as 
peculiaridades da colônia que alteraram as práticas e instituições metropolitanas implantadas, uma vez que a realidade colonial era diferente da realidade metropolitana.

De acordo com Jancsó, a crise do Antigo Regime europeu e do sistema colonial são panos de fundo, cenários que estabelecem os limites de ação e as possibilidades de solução para os homens da época em suas diferentes realidades coloniais. A crise europeia seria um pressuposto, um ponto de partida. Os processos emancipatórios precisam ser entendidos e explicados em suas nuances locais. (MALERBA, 2006: 41).

Contudo, a ideia de autonomia da colônia não deve invalidar a ideia de domínio e exploração da metrópole. A partir dessa concepção. é possível e necessário pensar a atuação da sociedade colonial dentro da estrutura estabelecida pelo pacto colonial.

Os trabalhos de pesquisa e os avanços teóricos [da década de 1970] tendiam a pôr crescentemente em questão as polaridades políticas apresentadas por Caio Prado Júnior, que opunham 'fazendeiros' e 'comerciantes' e, de forma bastante linear, 'nacionais' e 'portugueses'. Os estudos tendiam a criticar um acento, tido por excessivo, na dinâmica exportadora e chamava a atenção para o conhecimento insuficiente dos setores mercantis, e da produção agrícola voltada para o mercado interno, particularmente nas regiões que se encontravam articuladas ao mercado da Corte. (COSTA in JANCSÓ, 2005: 101).

Assim, o debate econômico ganhou força na década de 1980, com os estudos que enfocavam as transformações econômicas e sociais do final do século XVIII e início do século XIX, atentando para o contexto interno da colônia, especialmente no que se refere às questões comerciais como tráfico de escravos, comércio interprovincial.

Essa ênfase vinha convergir em parte para os resultados apresentados pela linha desenvolvida pelos orientandos de Maria Odila Silva Dias, combatendo a ideia de uma polarização entre interesses 'agrários' e 'mercantis' (e em decorrência, 'brasileiros' e 'portugueses'). Vistos desse modo, os interesses mercantis não poderiam ser pensados como estando "em oposição" aos grandes proprietários territoriais, nem como 'externos' à colônia. (COSTA in JANCSÓ, 2005: 107).

As nuances locais fazem emergir os sujeitos dentro do contexto com o qual eles se relacionam, o que permite um olhar mais profundo não apenas do aspecto econômico, mas também político e social.

A complexidade das relações entre os homens é essencial para compreender quais são as principais dificuldades da construção explicativa que o historiador pretende apresentar como 'história'. A complexidade das relações humanas é, sem dúvida, o problema essencial do objeto historiográfico. (ARÓSTEGUI, 2006: 307). 
As relações constituídas entre esses sujeitos revelam características, anseios, bem como a mentalidade da sociedade, aumentando as possibilidades de estudo da historiografia. A capacidade de escolha, bem como a atuação dos sujeitos que viveram o processo de Independência do Brasil, é entendida de maneira diferente, ao longo da historiografia. $\mathrm{O}$ estudo da atuação dos indivíduos no contexto colonial levou ao conhecimento da existência de relações sociais determinantes para compreender o período. Assim, percebeu-se que na colônia, indivíduos "criam relações dinâmicas e constantes com a sociedade, através de estratégias de aliança e jogos de interesses que se constroem e se refazem permanentemente ao seu redor" (MARTINS in FRAGOSO et al., 2007: 408).

Mais do que um cotejamento com as diversas abordagens historiográficas, faz-se importante o impacto e as possibilidades de uma tendência atual no pensar do ensino de História. A historiografia abre, nos anos 1990, um leque de estudos que "se dedicam a compreender o espaço do exercício da política como construção da esfera pública, fazendo emergir o conteúdo político complexo contido na esfera da cultura” (COSTA in JANCSÓ, 2005: 109). Essa produção pode ser um caminho para repensar a História Política, uma vez que oferece elementos que permitem perceber como se dá a articulação do social, do cotidiano e das mentalidades com o cenário político, que não deve ser pensado como algo extrínseco ao contexto social.

O campo do político e da ação política deixa de ser visto como um lugar separado, como uma 'instância', para ser concebido como lugar de articulação entre o plano social e sua representação, matriz simbólica na qual se enraíza experiência coletiva. (COSTA in JANCSÓ, 2005: 117).

Um emaranhado de alianças caracteriza os primórdios da vida da colônia, e o seu estudo permite uma análise da sociedade numa perspectiva econômica, política e social, cujas peculiaridades não vieram definidas nos navios com os colonizadores (PIÑEIRO in MENDONÇA, 2006), mas foram moldadas, de acordo com as necessidades e interesses dos indivíduos, o que permite pensar o processo de Independência como um processo que não pode ser datado, ou limitado a grandes acontecimentos.

As relações sociais são objetos de estudo de Iara Souza (SOUZA, 1999) que apresenta a ideia de um contrato social entre Dom Pedro I e seus súditos. Esse contrato entre a sociedade e o imperador precisava ser formalizado e a "assinatura" do mesmo seria a aclamação do imperador, e, por isso, a preocupação do governo com as festas e manifestações em honra do Rei, bem como as visitas do mesmo às províncias. As festas ao Rei "tornavam público o contrato que fundava o Brasil. O reconhecimento da legitimidade e dos elementos 
da ordem saía da esfera do segredo" (SOUZA, 1999: 268) criando no imaginário social a ideia de que toda a sociedade participa diretamente das decisões tomadas por um grupo restrito.

Isso explica a necessidade do imperador fazer-se uma figura com a qual a sociedade se identificasse, e permite que se questione a ideia de "inexistência da participação popular, mostrando que o Estado, a nacionalidade - e porque não dizer a cidadania - foram frutos dos embates entre grupos e facções. A praça pública influenciou sobremaneira a condução da política e dos destinos da nação que se formava" (RIBEIRO, 2007: 15). Ao pensar a construção de um contrato social entre a sociedade e seu representante, tira-se o príncipe regente da sombra das elites agrárias - que determinam os rumos do processo de Independência ao conduzirem as ações do príncipe - e mostra-se a relação de identificação e representação que se constrói entre os vários estratos sociais e Dom Pedro.

Assim, a Independência é vista, a partir da atuação dos indivíduos dentro do contexto, que é considerado em seu aspecto político, econômico e social, o que permite perceber as relações que são construídas, os interesses econômicos, políticos, a construção até mesmo do imaginário da época.

Esses estudos têm colocado vida nas estruturas - na colônia, na metrópole, no Estado - e trazem para o centro do estudo o caráter político do contexto em questão. Neles ressaltamse os indivíduos, os grupos, os debates e, sobretudo, o caráter tenso e construído do processo. É interessante observar que algumas dessas abordagens já se transpuseram em reflexões didáticas ou mesmo textos paradidáticos, mais à mão, portanto, dos professores do ensino básico ${ }^{3}$.

A natureza da classe e seus elementos de coesão - sua identidade, em suma aparecem como resultados de experiências comuns vividas por determinados homens, experiências essas que lhes possibilitam sentir e identificar seus interesses como algo que lhes é comum, e desta forma contrapor-se a grupos de homens cujos interesses são diferentes e mesmo antagônicos aos seus. (MATTOS, 1994: 4).

Quando a historiografia traz para o estudo do processo de Independência do Brasil uma análise voltada para a atuação dos sujeitos em seus complexos contextos sociais, percebe-se a possibilidade e a necessidade de um estudo da conjuntura política. O estudo sobre o príncipe regente, por exemplo, que é uma figura política, apresenta uma série de informações importantes, não apenas do cenário político, além de diversos elementos que caracterizam a sociedade da época. É possível analisar as elites que atuam diretamente na

\footnotetext{
${ }^{3}$ Ver Cadernos do Cedes - Vol. 1, n. 1 (1980) - São Paulo: Cortez; Campinas, CEDES, 1980; OLIVEIRA, Cecília Helena de Salles. A Independência e a Construção do Império. São Paulo: Atual, 1995, e 7 de Setembro de 1822: A Independência do Brasil. São Paulo: Companhia Editora Nacional, 2005; SOUZA, Iara Lis C. A Independência do Brasil. Rio de Janeiro: Jorge Zahar, 2000.
} 
política, mas também as demais classes da sociedade, que, embora não participem diretamente das decisões políticas, são sujeitos políticos, porque estão inseridas nesse contexto, como o qual se relacionam e com o qual, por vezes, se identificam.

É, a partir dessa discussão historiográfica que, no presente artigo, discute-se o processo de Independência do Brasil, tendo como objetivo complexificar a narrativa factual e cronológica que marca muitas produções didáticas. Discute-se, também, como a formação para a cidadania se realiza, ou não, no conteúdo dos livros didáticos, a partir da produção da Nova História, como orienta as diretrizes de ensino.

\section{O conteúdo dos livros didáticos e a formação para a cidadania.}

O Ministério da Educação (MEC) avalia o conteúdo dos livros didáticos, por meio do Plano Nacional do Livro Didático (PNLD) que, a cada três anos, publicam o Guia do Livro Didático, cujo objetivo é orientar os professores na escolha dos manuais a serem adotados nas escolas públicas. O conteúdo do livro didático, portanto, não se trata apenas de uma expressão do autor, ou dos autores, sobre suas concepções historiográficas. É o resultado das concepções dos autores adequadas às bases curriculares, mediadas pelo mercado.

Entre as dezesseis coleções apresentadas pelo Guia do Didático, para o triênio 20112013, este artigo analisa quatro coleções que foram adotadas por escolas públicas e municipais de Lavras: Projeto Araribá (APOLINÁRIO, 2007), Para Viver Juntos (REIS e MOTOOKA, 2009), História Sociedade e Cidadania (BOULOS, 2009), Projeto Radix (VICENTINO, 2009). ${ }^{4}$

Diante da semelhança do conteúdo, bem como da organização do mesmo nos livros didáticos, foi possível destacar quatro questões dentro do processo de Independência do Brasil: o ideal de Independência; a inserção das Conjurações Mineira (1789) e Baiana (1798) no processo de Independência; as transformações sociais provocadas pela chegada da Corte Portuguesa ao Brasil, em 1808, e a atuação do príncipe regente Dom Pedro.

Em todas as obras analisadas, a ideia de Independência vem acompanhada de uma relação com o cotidiano do aluno, de um convite à reflexão sobre o termo e, também, sobre o alcance ou não da Independência, da liberdade, para todos os setores da sociedade, seja por questões levantadas a partir de uma imagem de grande peso historiográfico, como $O$ Grito do Ipiranga, de Pedro Américo, que introduz a unidade analisada do livro Para Viver Juntos

\footnotetext{
${ }^{4}$ Segundo pesquisa feita em dezesseis escolas da cidade de Lavras, no ano de 2011, sete escolas adotaram para o triênio 2011 - 2013 a obra História Sociedade e Cidadania (BOULOS, 2009), três adotaram o livro Para Viver Juntos (REIS e MOTOOKA, 2009), três o Projeto Radix (VICENTINO, 2009), três o Projeto Araribá (APOLINÁRIO, 2007).
} 
(REIS e MOTOOKA, 2009), ou imagens que retratam eventos contemporâneos, como nas obras História Sociedade e Cidadania (BOULOS, 2009), e Projeto Radix (VICENTINO, 2009).

Entretanto, tais conceitos não são pensados dentro do contexto historiográfico estudado. Não se analisa como esse ideal de liberdade, de Independência se desenvolveu no Brasil. Valoriza-se o significado que o termo Independência tem hoje, como ocorre no Projeto Radix (VICENTINO, 2009) que utiliza imagens de protestos de estudantes, em SP, em 2001, que segundo o autor são contra a privatização, o Fundo Monetário Internacional e a política econômica, bem como a imagem de integrantes do Movimento dos Trabalhadores Sem Terra queimando uma bandeira com a sigla FMI em frente ao Banco Central, em 2004. O autor questiona o que é ser um país independente, e indaga aos leitores se os manifestantes consideravam o Brasil um país totalmente independente.

História Sociedade e Cidadania (BOULOS, 2009) justifica, no manual do professor, o uso de imagens de um desfile de 7 de setembro como estímulo à reflexão do aluno sobre o caráter "sacral e ritualístico" que envolve estas comemorações. Dirigindo-se ao professor, o autor ressalta que

a nosso ver, os desfiles cívicos podem tanto ser fator de socialização dos estudantes, sobretudo dos de tenra idade, como induzi-los a uma compreensão histórica do processo de Independência. Mas, com o apoio dos professores de Ciências Humanas, a comemoração de uma data cívica como o Sete de Setembro pode ser transformada também em um momento de reflexão e reavaliação de nosso passado à luz da experiência do presente. Questões podem ser levantadas ao longo ou ao final do capítulo: O que é Independência para você? Independência é uma ruptura ou um processo? Em 7 de setembro de 1822 o Brasil tornou-se independente de fato? O que mudou e o que permaneceu? (BOULOS Júnior, 2009)

Das perguntas propostas pelo autor, apenas as duas últimas serão respondidas ao longo do texto base do livro didático, respostas estas que indicam uma Independência política que se caracteriza pela manutenção da dependência econômica e dos interesses das elites brasileiras. A ideia de processo, em momento algum é trabalhada no texto, e a maneira como os fatos são apresentados levam à ideia de ruptura provocada, em razão da diferença de interesses entre metrópole e elites coloniais.

A obra de Pedro Américo, o Grito do Ipiranga, que ocupa uma página e meia da introdução do estudo da Independência do Brasil no livro Para Viver Juntos (REIS e MOTOOKA, 2009), é acompanhada dos seguintes dizeres:

os eventos políticos que ocorriam no Ocidente, como a Independência das colônias inglesas da América do Norte e a Revolução Francesa, levaram os habitantes do Brasil a contestar a ordem estabelecida na Colônia. A 
Independência do Brasil em 1822 é o resultado de um processo que se iniciou ainda no século XVIII, envolvendo brasileiros e portugueses. (REIS e MOTOOKA, 2009: 9)

O livro não apenas apresenta a raiz da Independência do Brasil no século XVIII, como aponta uma rivalidade entre brasileiros e portugueses, já no século XVIII, sendo que, mesmo no século XIX, essa questão da nacionalidade não estava definida (RIBEIRO, 2002). O que existiam eram portugueses que nasciam na metrópole e portugueses que nasciam na colônia.

Ainda que a avaliação do Guia do Livro Didático (BRASIL, 2010) aponte para a necessidade de complementar o texto base desta obra, avaliado como sintético, ao insinuar uma rivalidade entre brasileiros e portugueses no século XVIII, o livro indica a existência de um sentimento de brasilidade que não se confirma segundo novas pesquisas, já que foi apenas durante os primeiros anos do Império que "se foi definindo o que era 'ser brasileiro' em oposição ao 'ser português'. (RIBEIRO, 2002: 21).

Importante dizer que as questões levantadas no início da unidade, com relação aos conceitos liberdade e Independência são interessantes, em especial por levar o aluno a se colocar diante desses valores. Relevante também é o convite para a análise de uma pintura extremamente significativa para o estudo, não só do processo de Independência, como também da ideia que se construiu sobre esse processo, o que poderia ser introduzido a partir da última questão proposta: "Em sua opinião, que mensagem o artista quis transmitir ao pintar essa cena?" (REIS e MOTOOKA, 2009: 9)

Entretanto, o texto desse livro, bem como das demais obras analisadas, não fornece bases para que os conceitos de liberdade e Independência sejam discutidos a fundo.

A obra Projeto Araribá (APOLINÁRIO, 2007) vislumbra, de maneira breve, em sua introdução à unidade, analisar o contexto colonial, partindo da ideia de identificação entre os colonos e o rei de Portugal, e da noção do pertencimento ao Império Luso, o que, segundo a obra, torna difícil a construção de uma nacionalidade brasileira, que entende ser um sentimento compartilhado pela coletividade.

A autora não só problematiza a questão da nacionalidade no contexto do processo de Independência como estabelece uma comparação com o presente, ao apresentar, os critérios determinados pela Constituição Federal para que um indivíduo seja considerado cidadão brasileiro. Também, amplia a noção de nacionalidade ao defini-la como "um sentimento partilhado por uma coletividade, que se reconhece ligada por uma identidade históricocultural comum" (APOLINÁRIO, 2007: 150).

Embora seja significativa a intenção de aproximar a Independência do Brasil, o século XIX, do cotidiano do aluno, o fato de não haver uma discussão sobre a noção de 
Independência, de liberdade no contexto do século XIX, assim como nos demais livros, leva os alunos a entenderem o movimento de Independência, a partir do significado que o termo tem hoje, direcionando a compreensão do leitor para uma ideia de separação, que leva a uma ideia de descontentamento.

A contextualização do termo Independência permitiria que se entendesse a complexidade da sociedade colonial, porque torna possível compreender como se forma o ideário social. Como surge a ideia de Independência; o que levou essa sociedade a falar sobre essa questão.

Com relação às Conjurações Mineira (1789) e Baiana (1798), com exceção da obra Projeto Radix (VICENTINO, 2009), os livros analisados inserem esses movimentos no mesmo capítulo ou unidade do processo de Independência, contribuindo para uma concepção de causa e consequência entre os eventos. As obras não discutem os ideais de Independência e liberdade no contexto das conjurações, e, ainda, que o Projeto Araribá (APOLINÁRIO, 2007) saliente no texto base que a questão do caráter separatista da Conjuração Mineira (1789) é uma questão polêmica entre os estudiosos, o movimento é estudado no tema intitulado "A crise do Antigo Sistema Colonial” (APOLINÁRIO, 2007: 155), o que leva a compreender o movimento por um viés separatista.

Entretanto, é positiva a possibilidade de questionamento na sessão "Um problema" (APOLINÁRIO, 2007: 157), na qual a autora destaca um fragmento de Luiz Carlos Villalta (VILLALTA, 2000: 53 - 54) em que o autor aponta semelhanças e diferenças entra a Conjuração Mineira (1789) e outras revoltas coloniais. As três perguntas propostas para a análise do fragmento, não são muito complexas, mas contribuem para que o aluno reflita sobre o movimento, a partir de uma fonte historiográfica que questiona o mesmo.

Os quatro manuais analisados salientam a relação do processo de Independência com o contexto europeu, em razão da imposição do Bloqueio Continental que levou a Corte Portuguesa a transferir-se para sua colônia na América. Percebe-se, entretanto, que as transformações provocadas com a chegada da Corte se resumem à instalação das instituições administrativas necessárias à manutenção do governo do Império, e às mudanças de hábitos dos colonos que passaram a adotar hábitos europeus. Ainda assim, pouco se fala da sociedade, ou como era a vida na capital da colônia quando a Corte chegou.

O texto dos livros não permite compreender que o impacto da chegada da Corte vai além da instalação das instituições administrativas no Rio de Janeiro e da mudança das vestimentas dos colonos. Não é possível que se compreenda, especialmente, que a presença da 
Corte passa pela aceitação da sociedade bem como pela negociação entre o monarca e seus súditos. Mas para que se compreenda isso é preciso dar voz a esses súditos.

"Quanto ao papel representado por Dom Pedro ele é todo ocasional (...) com a partida de Dom João pode ele com toda facilidade levar adiante os planos do 'partido brasileiro' e realizar a separação do país" (PRADO Júnior, 1993: 53). Essa pequena citação resume a visão que os quatro livros didáticos apresentam da participação do príncipe regente no processo de Independência do Brasil. Visão esta que faz-se bastante clara, por exemplo, na obra Projeto Araribá (APOLINÁRIO, 2007), que insere a figura do príncipe regente no contexto do processo de Independência com o subtítulo "Dom Pedro e as elites" (APOLINÁRIO, 2007: 165). As quatro obras focam na articulação do Partido Brasileiro junto ao príncipe, para impedir que a sociedade se mobilizasse e colocasse em risco a ordem da monarquia escravista, contrariando os interesses das elites.

Os livros didáticos retiraram o foco dos heróis e dos grandes marcos. Dessa forma, atendem à exigência de uma mudança de postura que teria como objetivo construir uma nova concepção de História, a partir de uma História que prime pelo social, mas mantiveram uma leitura voltada para estruturas impessoais, das quais os indivíduos são meros suportes (Cf. THOMPSON, 1981).

Uma vez que a História não é linear, os livros didáticos podem assumir uma linha historiográfica, uma vez que o debate historiográfico é corrente, e, sendo assim, os livros estariam no seu direito de assumir uma das diversas visões do processo histórico. É digno de destaque que, mesmo diante da orientação das diretrizes nacionais para o trabalho com as novas concepções de História, voltadas para o social, para a formação de cidadãos questionadores, essa nova historiografia seja pouco mencionada no texto base dos livros didáticos, ou em boxes informativos, ou textos complementares. As obras analisadas pouco usam desses artifícios para introduzir um diálogo entre as linhas historiográficas, e se o fazem, no livro do aluno, ou no manual do professor, o texto base não sustenta uma postura crítica que possa de fato gerar uma reflexão profunda, e contribuir para a compreensão da provisoriedade das conclusões da pesquisa historiográfica, ou mesmo atender às expectativas das diretrizes nacionais de uma formação para a cidadania.

As reflexões sobre os princípios do pensamento histórico determinantes para a história como ciência podem, no campo da historiografia, fazer com que a formulação historiográfica de resultados de pesquisa capacite seus destinatários a abordar a intepretação do passado que lhes é oferecida usando seu entendimento próprio, e não meramente pela imposição do entendimento do autor. (RÜSEN, 2001: 47). 
Essa noção da provisoriedade e de leituras contraditórias da História, se pensada no contexto do processo de Independência do Brasil, permite que se perceba a História como fruto de seu tempo, e da atuação do historiador sobre suas fontes, em diálogo com trabalhos anteriores. É possível, também, enxergar uma construção acerca do ideal de Independência que se torna um fio condutor para a análise do contexto social do século XIX, ao vislumbrar o ideário dessa sociedade que, ainda sob a égide do Pacto Colonial e do Reino Unido, constrói suas particularidades.

Olhar para a sociedade, para o cotidiano, não deve pressupor o abandono do político e do econômico em prol do social. Os sujeitos atuam, ao mesmo tempo, em todas essas esferas, com maior ou menor intensidade, mas até mesmo isso é um dado sobre o contexto. É possível, assim, questionar a extinção dos indivíduos tipificados como "heróis" da História. Os livros procuram não focar o processo de Independência na figura de Dom Pedro, entretanto, o foco em um grande herói é redirecionado para a elite colonial que orquestra o processo. Analisar Dom Pedro I dentro do contexto da Independência é atender à orientação das diretrizes que indicam a necessidade de problematizar a História, ao passo que insere no estudo da História elementos da produção da nova historiografia, e, ainda, enriquece esse discurso, ao permitir um diálogo entre a Nova História e as outras concepções de História.

Os livros didáticos materializam esse momento de transição do ensino da História, no qual sequer as diretrizes educacionais conseguem ser coerentes em seus objetivos. Elas buscam a construção de uma noção de História em construção, como forma de atingir o objetivo maior da formação para cidadania, por meio da inserção da Nova História nos livros didáticos, como meio de aproximar o aluno dos processos históricos. Entretanto, ainda que os livros se esforcem para realizar essa aproximação, as narrativas continuam arraigadas a uma história voltada para as estruturas sem vida, sem sujeitos, em um cenário onde não se vê a prática da cidadania.

Os livros didáticos têm dificuldades em apresentar toda renovação historiográfica que sugerem as diretrizes educacionais. Dentro de suas "possibilidades" eles mantêm a narrativa voltada para o trato das estruturas, do cenário econômico, das elites, e retiram, ou minimizam no processo, os "heróis", os eventos significativos do espaço público, a política e o povo. A aproximação entre o aluno e a História não se dá pela problematização da mesma, mas pela inserção de elementos e conceitos do tempo presente para a análise dos Oitocentos, sem levar em consideração as peculiaridades de cada contexto histórico.

\section{Possibilidades para a construção de uma História Política que forme para a cidadania.}

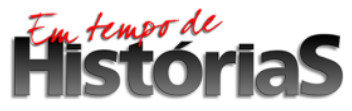


O exercício de articular a produção historiográfica para o estudo do processo de Independência mostra como um olhar mais aprofundado sobre a atuação dos sujeitos em seus contextos permite a construção de um conhecimento ainda mais rico dos processos históricos. Esse olhar é que permite que se perceba a existência de um processo que não se esgota em movimentos estruturais, e cujo desenrolar depende das ações de indivíduos, em associação, mas que, no campo escolar é fortemente ligado a um processo de individuação. (Cf. RÜSEN, 2007).

Ao levarem em consideração as peculiaridades da colônia e da Independência, ao fazerem uma análise do social e das relações que se formam nesse contexto, as pesquisas iluminam a compreensão sobre o cenário político, permitindo-se, até mesmo "resgatar os heróis", porque não são vistos como os únicos sujeitos do processo. Tal leitura compreende a figura do herói como um dos muitos sujeitos do processo, cuja posição destacada dentro do mesmo, não revela um apreço à história das elites, ou desapego à história social, mas um emaranhado de relações que culminam na aceitação/identificação, na relação do mesmo com um contexto social, revelando os anseios dessa sociedade na qual essa figura também está inserida.

Essa visão do espaço público no contexto do processo de Independência é, por exemplo, um convite a se pensar a questão da cidadania, pois não apenas indica uma movimentação social como apresenta a possibilidade desse social desafiar o governo, ou seja, a possibilidade de lutar por seus interesses. A praça pública é o local onde os valores de cidadania, de participação e luta social acontecem no século XIX, e onde podemos pensar a construção da ideia de cidadania, de participação popular no contexto do processo de Independência ${ }^{5}$.

O estudo da Nova História Política elenca elementos e ações que compõem o cenário das relações sociais, que também são relações políticas. $\mathrm{O}$ olhar para o interior do Reino Unido, a busca por uma releitura da política e do social, abre uma possibilidade para “politizar" a leitura que a Nova História faz do cotidiano, dos indivíduos, a micro-história.

A reinterpretação dos elementos que corporificam a política e o poder; as representações sociais e coletivas, os imaginários sociais, a memória ou memórias coletivas, as mentalidades e as práticas discursivas associadas ao poder direcionam os estudos políticos para o universo societário de tal maneira que, não se estuda mais a política apenas como estudo do Estado ou

\footnotetext{
${ }^{5}$ Ver MOREL, Marco. As Transformações dos Espaços Públicos: imprensa, atores políticos e sociabilidades na cidade imperial (1820-1840). São Paulo, HUCITEC, 2005.
} 
das guerras, mas, como ação negociada e forjada na sociedade em conexão com a cultura. (CARDOSO; VAINFAS apud SANTOS NETO, 2008: 139).

Assim, a Nova História fornece elementos para que se escreva uma Nova História Política, pois é possível que a política seja percebida como uma extensão do social, e é dentro desse cenário complexo, no qual interagem os aspectos políticos, econômicos e sociais onde encontramos o caminho para que o Ensino de História consiga atingir o objetivo principal das diretrizes sociais: a formação para a cidadania.

Mas o que se pretende pontuar quando se fala numa Nova História política? Pretende-se chamar atenção dos professores para a inserção, nas abordagens de temas essencialmente políticos, da dimensão social; pois pensar o Estado brasileiro na sala de aula, neste início do século XXI, significa propor questionamentos sobre a participação da população, o exercício da política, o uso político dos sistemas de representações e o lugar de cada um dentro de uma sociedade administrada por instituições, sejam elas: coloniais, imperiais ou republicanas. (SANTOS NETO, 2008: 140).

A Nova História Política apresenta-se como um caminho eficiente para que o ensino da História atenda aos objetivos das diretrizes educacionais de uma formação cidadã, já que faz possível a percepção da atuação dos diversos estratos sociais e indivíduos, levando em consideração sua influência em todos os âmbitos do contexto social, o que, a nosso ver é o que se espera da formação para a cidadania, uma vez que o cidadão se encontra imerso em um contexto no qual política, economia e sociedade são intrínsecas.

\section{Referências Bibliográficas}

ALVIM, Yara Cristina. O livro didático na batalha de ideias: vozes e saber histórico no processo de avaliação do PNLD. Dissertação (Mestrado em Educação) - UFJF, Juiz de Fora, 2010.

APOLINÁRIO, Maria Raquel. Projeto Araribá: História/ obra coletiva, concebida, desenvolvida e produzida pela Editora Moderna: editora responsável Maria Raquel Apolinário - São Paulo: Moderna

ARÓSTEGUI, Julio. A pesquisa histórica: teoria e método. Bauru: EDUSC, 2006.

BICALHO, Maria Fernanda Baptista. O que significa ser cidadão nos tempos coloniais. In: ABREU, Martha; SOIHET, Rachel. Ensino de História: conceitos, temáticas e metodologias. Rio de Janeiro: Casa da Palavra, 2003.

BOULOS Júnior, Alfredo. História: sociedade e cidadania. São Paulo: FTD, 2009.

Brasil. Secretaria de Educação Fundamental. Parâmetros curriculares nacionais: história / Brasília: MEC /SEF, 1998.

BUFFA, Ester; ARROYO, Miguel; NOSELLA, Paolo. Educação e Cidadania: quem educa o cidadão? - 11. ed. - São Paulo, Cortez, 2003.

CAIMI, Flávia Eloisa; MACHADO, Ironita A. P.; DIEHL, Astor Antônio. O livro didático e o currículo de história em transição. $2^{\mathrm{a}}$ edição. Passo Fundo: UFP, 2002 
COSTA, Willma Perez. A Independência na historiografia brasileira. In: JANCSÓ, Istiván (org). Independência: História e Historiografia. São Paulo: HUCITEC: FAPESP, 2005.

FERREIRA, Marieta de Moraes. A Nova "Velha História”: o retorno da História Política. Revista Estudos Históricos, Vol. 5, no 10 (1992).

GATTI Júnior, Décio. Estado, Currículo e Livro Didático de História no Brasil (1988 - 2007) In: OLIVEIRA, Margarida Maria Dias de; STAMATTO, Maria Inês (orgs.) "O livro didático de História: políticas educacionais, pesquisa e ensino”. Natal: EDUFRN, 2007

GOMES, Angela de Castro. Venturas e desventuras de uma república de cidadãos. In: ABREU, Martha; SOIHET, Rachel. Ensino de História: conceitos, temáticas e metodologias. Rio de Janeiro:Casa da Palavra, 2003. p. 152

Guia de Livros Didáticos: PNLD 2011: História - Brasília: Ministério da Educação, Secretaria de Educação Básica, 2010

HESPANHA. Antônio Manuel, "A constituição do Império Português - Revisão de alguns enviesamentos e correntes”. In: FRAGOSO, João; BICALHO, Maria; GOUVEA, Maria (org.).”O Antigo Regime nos Trópicos”. Rio de Janeiro: Civilização Brasileira, 2001.

HOUAISS, Antônio. Dicionário Houaiss da Língua Portuguesa. Rio de Janeiro: Objetiva, 2001.

MALERBA, Jurandir. A Independência brasileira: novas dimensões. Rio de Janeiro: Editora FGV, 2006

MARTINS, Maria Fernanda. Os tempos de mudança: elites, poder e redes familiares no Brasil, séculos XVIII e XIX. In: FRAGOSO, João Luís R. et alii (orgs). Conquistadores e negociantes: história de elites no Antigo Regime nos Trópicos. América lusa, séculos XVI a XVIII. Rio de Janeiro: Civilização Brasileira, 2007.

MATTOS, Ilmar Rohloff de. O tempo saquarema - a formação do Estado imperial. Rio de Janeiro: ACCESS, 1994.

NETO, Manoel Pereira de Macedo. Parâmetros Curriculares Nacionais de História: desafios e possibilidades da história ensinada na Educação Básica. Revista História em Reflexão: Vol. 3 n. 6 - UFGD - Dourados. jul/dez 2009.

NOVAIS, Fernando A,; MOTA, Carlos Guilherme. “A Independência Política do Brasil”. São Paulo: HUCITEC, 1996. $2^{\mathrm{a}} \mathrm{Ed}$

OLIVEIRA, Cecília Helena de Salles. A Astúcia Liberal.: relações de mercado e projetos políticos no Rio de Janeiro. Bragança paulista, EDUSF e ÍCONE, 1999.

. A Independência e a Construção do Império. São Paulo: Atual, 1995

PIÑEIRO, Théo Lobarinhas. As classes sociais na construção do Império do Brasil. In: MENDONÇA, Sônia Regina de (org). Estado e historiografia no Brasil. Niterói: EDUFF, 2006.

PRADO Júnior, Caio. Evolução Política do Brasil - Colônia e Império. São Paulo: Editora Brasiliense. $1^{\mathrm{a}}$ edição, 1993.

PURIFICAÇÃO, Ana Tereza de Souza e Castro da. (Re)criando interpretações sobre a Independência do Brasil: um estudo das mediações entre memória e história nos livros didáticos. Dissertação (mestrado) Faculdade de Filosofia, Letras e Ciências Humanas - USP. São Paulo, 2002.

REIS, Anderson Roberti dos; MOTOOKA, Débora Yumi. Para Viver Juntos. São Paulo: Edições SM, 2009.

REMOND, René. Por que a História Política? Revista Estudos Históricos, Vol. 7, № 13, 1994.

RIBEIRO, Gladys Sabina. A liberdade em construção. Rio de Janeiro: Relume-Dumará/ FAPERJ, 2002.

Cidadania, liberdade e participação no processo de autonomização do Brasil e nos projetos de construção da identidade nacional. Locus: Revista de História. Juiz de Fora v.13. nº1. p. 11 - 33, 2007.

RÜSEN, Jörn. História viva: Teoria da História III: formas e funções do conhecimento histórico. Brasília: Editora da Universidade de Brasília, 2007.

Razão Histórica: Teoria da história: os fundamentos da ciência histórica. Brasília. Editora da Universidade de Brasília, 2001.

SANTOS NETO, Martinho Guedes dos. Cultura Política e Poder: Perspectivas para o Ensino de História. In: SANTOS NETO, Martinho Guedes dos. (org) História Ensinada: Linguagens e a Abordagens em Sala de Aula. João Pessoa: Ideia, 2008. 
SOUZA, Iara Lis C. "Pátria Coroada: o Brasil como corpo político autônomo - 1780-1831”. Fundação Editora da UNESP, 1999.

THOMPSON, Edward P. A miséria da teoria ou um planetário de erros: uma crítica ao pensamento de Althusser. Rio de Janeiro: Zahar, 1981.

VICENTINO, Cláudio Roberto. Projeto Radix. São Paulo: Editora Scipione, 2009

VILLALTA, Luiz Carlos. 1789 - 1808. O império luso-brasileiro e os brasis. São Paulo: Companhia das Letras, 2000. 